\title{
Rare and Unusual Choroidal Abnormalities in a Patient with Systemic Lupus Erythematosus
}

\author{
Shinji Makino Hironobu Tampo \\ Department of Ophthalmology, Jichi Medical University, Tochigi, Japan
}

\section{Key Words}

Systemic lupus erythematosus - Choroidal abnormality · Near-infrared reflectance · Neurofibromatosis type 1

\begin{abstract}
Purpose: To report a case of rare and unusual choroidal abnormalities in a 42-year-old woman with systemic lupus erythematosus (SLE). Methods: Images were obtained using fundus photography, fluorescein angiography, near-infrared reflectance (NIR) imaging, and optical coherence tomography (OCT). Results: The patient had a history of SLE and central retinal artery occlusion in her right eye. Fundus examination showed no specific retinochoroidal abnormalities, with the exception of optic disc atrophy in her right eye and a peripapillary small hemorrhage in her left eye. However, NIR revealed multiple bright patchy lesions in the choroid of the posterior pole and the mid-periphery of the fundus in both eyes. OCT demonstrated irregular hyperreflectivity at the lesion sites. Conclusions: The observed choroidal abnormalities are highly specific findings and therefore indicative of neurofibromatosis type 1 (NF1). Since the coexistence of SLE and NF1 is extremely rare, this case provided the chance to examine the relationship between SLE and NF1.
\end{abstract}

\section{Introduction}

In 2000, Yasunari et al. [1] suggested that choroidal abnormalities were easily detectable by an infrared light examination with a scanning laser ophthalmoscope in $100 \%$ of their neurofibromatosis type 1 (NF1) patients. Recently, the choroidal abnormalities that can be detected by near-infrared reflectance (NIR) have been recognized as being highly specific 
Makino et al.: Rare and Unusual Choroidal Abnormalities in a Patient with Systemic Lupus Erythematosus

findings for NF1 [2]. The cutoff value for choroidal nodules that can be detected by NIR was reported to be 1.5 [2]. Different imaging modalities, including NIR, near-infrared autofluorescence and optical coherence tomography (OCT), demonstrated that the choroid is affected by NF1 [3-5].

Systemic lupus erythematosus (SLE) is an autoimmune, episodic, multisystem disease characterized by a widespread inflammation of both the blood vessels and connective tissues, accompanied by an increase in antibodies targeting the components of the cell nucleus [6]. Choroidopathy is a rare disorder in SLE [7].

Here, we report a case of SLE with choroidal abnormalities detected by NIR, usually reported in NF1 patients.

\section{Case Report}

A 42-year-old woman complaining of transient blindness in her left eye was referred to our hospital. The patient had a history of SLE and central retinal artery occlusion in her right eye that occurred at the age of 33 years. On initial examination, she had a best-corrected visual acuity of 1.2 in the left eye and no light perception in the right eye. Ocular pressures and anterior segments were normal (fig. 1a, e). Fundus examination showed no specific retinochoroidal abnormalities with the exception of optic disc atrophy due to central retinal artery occlusion in her right eye (fig. 1b) and a peripapillary small hemorrhage in her left eye (fig. 1f). Fluorescein angiography revealed no dye leakage and pooling (fig. 1c, g). However, NIR (Heidelberg Retina Angiograph 2, Heidelberg Engineering, Heidelberg, Germany) showed multiple bright patchy lesions in the choroid of the posterior pole and the midperiphery of the fundus in both eyes (fig. 1d, h). OCT (RS-3000, NIDEK, Gamagori, Japan) images of these lesions revealed irregular, hyperreflective choroidal foci (fig. 2).

Administration of oral steroids was continued and her laboratory values were as follows: hemoglobin $9.1 \mathrm{~g} / \mathrm{dl}$, hematocrit $29.3 \%$, WBC count $6,900 / \mathrm{mm}^{3}$ and platelet count $223,000 / \mathrm{mm}^{3}$. No atypical cells were found during a peripheral blood smear. C-reactive protein was $0.97 \mathrm{mg} / \mathrm{dl}$ (normal $<0.06 \mathrm{mg} / \mathrm{dl}$ ). Hepatic and renal function tests and electrolytes were within normal limits. Urinalysis was normal. C3 and C4 complement fractions were 64 and $11 \mathrm{mg} / \mathrm{dl}$, respectively (normal values are $86-160$ and $17-45 \mathrm{mg} / \mathrm{dl}$, respectively). Anti-double-stranded DNA antibody was $125.1 \mathrm{IU} / \mathrm{ml}$ (normal $<12.0 \mathrm{IU} / \mathrm{ml}$ ). Cranial magnetic resonance imaging findings were unremarkable.

\section{Discussion}

To the best of our knowledge, this is the first report to ever be published in the literature of a patient with SLE who was diagnosed with NIR.

In 2012, Viola et al. [2] reported that choroidal nodules detected by NIR imaging were present in 79 (82\%) of 95 NF1 patients. Similar abnormalities were present in 7\% out of 100 healthy subjects. This previous study also showed that the highest accuracy for NIR imagery detection was obtained when using a cutoff value of 1.5 choroidal nodules. Sensitivity and specificity of the examination at the optimal cutoff point were 83 and $96 \%$, respectively. Both of these values were in line with the most commonly used diagnostic criteria of the National Institutes of Health (NIH) [8]. Viola et al. [2] recommend that the NIR examination, which can detect choroidal involvement, should be considered as a new diagnostic criterion for NF1. Regardless of the real prevalence of choroidal involvement, the presence of the 
Makino et al.: Rare and Unusual Choroidal Abnormalities in a Patient with Systemic Lupus Erythematosus

bright patchy lesions seen with NIR imaging appears to be highly specific for NF1 [2]. In this previous report, 7 control subjects with bright patchy nodules were detected when using NIR. However, 3 subjects only had one bright nodule in one eye as a result of a choroidal nevus. In the other 4 control subjects, the bright nodules were probably the result of atrophic areas, vitreoretinal reflex, or optical reflectance artifacts. In our patient, choroidal abnormalities showed multiple lesions, and fluorescein angiography images revealed no atrophic lesions. Moreover, no choroidal nevus or any other optical artifacts were observed in any of the images. Additionally, OCT confirmed the choroidal localization of these abnormalities. However, our patient did not present with café-au-lait spots, cutaneous neurofibroma, iris Lisch nodules, glioma, osseous lesion, nor did she have any first-degree relative with NF1. Therefore, she was not diagnosed as having NF1 based on the NIH criteria [8].

In SLE, cotton wool patches and retinal hemorrhage are commonly found. In contrast, choroidopathy is considered to be a rare disorder in SLE patients [7]. It has also been shown that immunosuppressive treatments with steroids in SLE patients can potentially modify their choroidal and retinal findings. For example, occlusive retinal vasculitis, retinal pigment epithelial dysfunction, such as retinal pigment epithelial detachment, along with choroidal neovascularization and multiple posterior pigment epitheliopathy, have all been reported to be complications associated with treatments in SLE patients. It has also been suggested that long-term steroid therapy is probably responsible for the subsequently observed retinal pigment epithelial complications [7]. In our current case, however, choroidal abnormalities, known to be highly specific for NF1, were detected.

Therefore, this case proved to be interesting as it provided a chance to examine the relationship between SLE and NF1. In addition, we speculated that there may be a relationship rather than an incidental association between SLE and choroidal abnormalities. The coexistence of SLE and NF1 is extremely rare [6, 9-13]. In 1975, Bitnun and Bassan [9] examined 2 patients who initially developed SLE and then were subsequently diagnosed as having NF1. In a further report by Riccardi [10], a patient was first diagnosed as having SLE, and then 2 years later, she developed nodular subcutaneous neurofibromas. The authors of both of these previous reports hypothesized that this association might either be coincidental or perhaps be due to viral infections. Corominas et al. [11] examined a patient who developed SLE 5 years after NF1 and speculated that this association might have simply been a matter of coincidence. Akyüz et al. [6] also examined a 9-year-old girl, who, after initially developing NF1, subsequently was diagnosed as having SLE.

Possible explanations for the coexistence of SLE and NF1 have been previously proposed by Akyüz et al. [6]. Due to the impaired immune regulation that is present in SLE, they hypothesized that the lack of neurofibromin might be responsible for causing the autoimmune disease. Other previous studies have demonstrated that NF1 is caused by the inactivation of the $N f 1$ tumor suppressor gene, which encodes the protein neurofibromin [13-15]. Moreover, neurofibromin inhibits the proliferation of astrocytes, myeloid cells, and melanocytes [16]. Since neurofibromin functions as a guanosine triphosphatase-activating protein for Ras in T cells, it plays an essential role in lymphocyte development and function. Neurofibromin has also been shown to negatively regulate Ras activity [16]. Ingram et al. [17] studied lymphoproliferative defects in mice lacking the expression of neurofibromin and discovered that the absence of neurofibromin in $\mathrm{T}$ cells resulted in an enhanced Ras activation. Kim et al. [18] additionally reported that, although neurofibromin plays a negative regulator role in the proliferation of many cell types, it may also be a positive regulator of lymphocyte proliferation. Gerosa et al. [19] reported that anti-double-stranded DNA antibodies and immune complexes were present in NF1 patients, even though there 
Makino et al.: Rare and Unusual Choroidal Abnormalities in a Patient with Systemic Lupus Erythematosus

were low titers. Thus, according to the above hypothesis, the lack of neurofibromin in NF1 could be related to the SLE autoimmune disease due to this impaired immune regulation.

In conclusion, although our current findings were based on a single case, long-term follow-up and additional cases will need to be examined so that these rare and unusual associations between SLE and choroidal abnormalities can definitively be characterized.

\section{Disclosure Statement}

The authors have no conflicts of interest.

\section{References}

1 Yasunari T, Shiraki K, Hattori H, Miki T: Frequency of choroidal abnormalities in neurofibromatosis type 1. Lancet 2000;356:988-992.

-2 Viola F, Villani E, Natacci F, Selicorni A, Melloni G, Vezzola D, Barteselli G, Mapelli C, Pirondini C, Ratiglia R: Choroidal abnormalities detected by near-infrared reflectance imaging as a new diagnostic criterion for neurofibromatosis 1. Ophthalmology 2012;119:369-375.

-3 Nakakura S, Shiraki K, Yasunari T, Hayashi Y, Ataka S, Kohno T: Quantification and anatomic distribution of choroidal abnormalities in patients with type 1 neurofibromatosis. Graefe Arch Clin Exp Ophthalmol 2005;243:980-984.

4 Ayata A, Unal M, Ersanli D, Tatlipinar S: Near infrared fluorescence and OCT features of choroidal abnormalities in type 1 neurofibromatosis. Clin Exp Ophthalmol 2008;36:390-392.

5 Ueda-Consolvo T, Miyakoshi A, Ozaki H, Houki S, Hayashi A: Near-infrared fundus autofluorescencevisualized melanin in the choroidal abnormalities of neurofibromatosis type 1. Clin Ophthalmol 2012;6:1191-1194.

-6 Akyüz SG, Çaltik A, Bülbül M, Erdoğan Ö, Renda R, Demircin G: An unusual pediatric case with neurofibromatosis and systemic lupus erythematosus. Rheumatol Int 2012;53:227-249.

7 Edouard S, Douat J, Sailler L, Arlet P, Astudillo L: Bilateral choroidopathy in systemic lupus erythematosus. Lupus 2011;20:1209-1210.

-8 Gutmann DH, Aylsworth A, Carey JC, Korf B, Marks J, Pyeritz RE, Rubenstein A, Viskochil D: The diagnostic evaluation and multidisciplinary management of neurofibromatosis 1 and neurofibromatosis 2. JAMA 1997;278:51-57.

-9 Bitnun S, Bassan H: Letter: neurofibromatosis and SLE. N Engl J Med 1975;292:429-430.

$\$ 10$ Riccardi VM: Neurofibromatosis in a patient with systemic lupus erythematosus. Arthritis Rheum $1983 ; 26: 574$.

11 Corominas H, Guardolia JM, Matas L, Vazquez G: Neurofibromatosis and systemic lupus erythematosus. A matter of coincidence? Clin Rheumatol 2003;22:496-497.

Bassan HM, Bitnun S: Systemic lupus erythematosus and neurofibromatosis. Int J Dermatol 1976;15:36-37.

13 Cawthon RM, Weiss R, Xu G, Viskochil D, Culver M, Stevens J, Robertson M, Dunn D, Gesteland R, O'Connell P, White R: A major segment of the neurofibromatosis type 1 gene: cDNA sequence, genomic structure, and point mutations. Cell 1990;62:193-201.

-14 Wallace MR, Marchuk DA, Andersen LB, Letcher R, Odeh HM, Saulino AM, Fountain JW, Brereton A, Nicholson J, Mitchell AL, Brownstein BH, Collins FS: Type 1 neurofibromatosis gene: identification of a large transcript disrupted in three NF1 patients. Science 1990;249:181-186.

15 Andersen LB, Ballester R, Marchuk DA, Chang E, Gutmann DH, Saulino AM, Camonis J, Wigler M, Collins FS: A conserved alternative splice in the von Recklinghausen neurofibromatosis (NF1) gene produces two neurofibromin isoforms, both of which have GTPase-activating protein activity. Mol Cell Biol 1993;13:487495.

16 Ingram DA, Yang FC, Travers JB, Wenning MJ, Hiatt K, New S, Hood A, Shannon K, Williams DA, Clapp DW: Genetic and biochemical evidence that haploinsufficiency of the $N f 1$ tumor suppressor gene modulates melanocyte and mast cell fates in vivo. J Exp Med 2000;191:181-188.

17 Ingram DA, Zhang L, McCarthy J, Wenning MJ, Fisher L, Yang FC, Clapp DW, Kapur R: Lymphoproliferative defects in mice lacking the expression of neurofibromin: functional and biochemical consequences of $N f 1$ deficiency in T-cell development and function. Blood 2002;100:3656-3662.

18 Kim TJ, Cariappa A, Iacomini J, Tang M, Shih S, Bernards A, Jacks T, Pillai S: Defective proliferative responses in B lymphocytes and thymocytes that lack neurofibromin. Mol Immunol 2002;38:701-708.

19 Gerosa PL, Vai C, Bizzozer L, Fontana A, Giussani G, Spinelli M: Immunological and clinical surveillance in Recklinghausen's Neurofibromatosis (NF1). Panminerva Med 1993;35:80-85. 
Case Reports in

Ophthalmology

\begin{tabular}{l|l}
\hline Case Rep Ophthalmol 2013;4:81-86 \\
\hline DOI: 10.1159/000354288 & $\begin{array}{l}\text { ○ 2013 S. Karger AG, Basel } \\
\text { www.karger.com/cop }\end{array}$ \\
\hline
\end{tabular}

Makino et al.: Rare and Unusual Choroidal Abnormalities in a Patient with Systemic Lupus Erythematosus
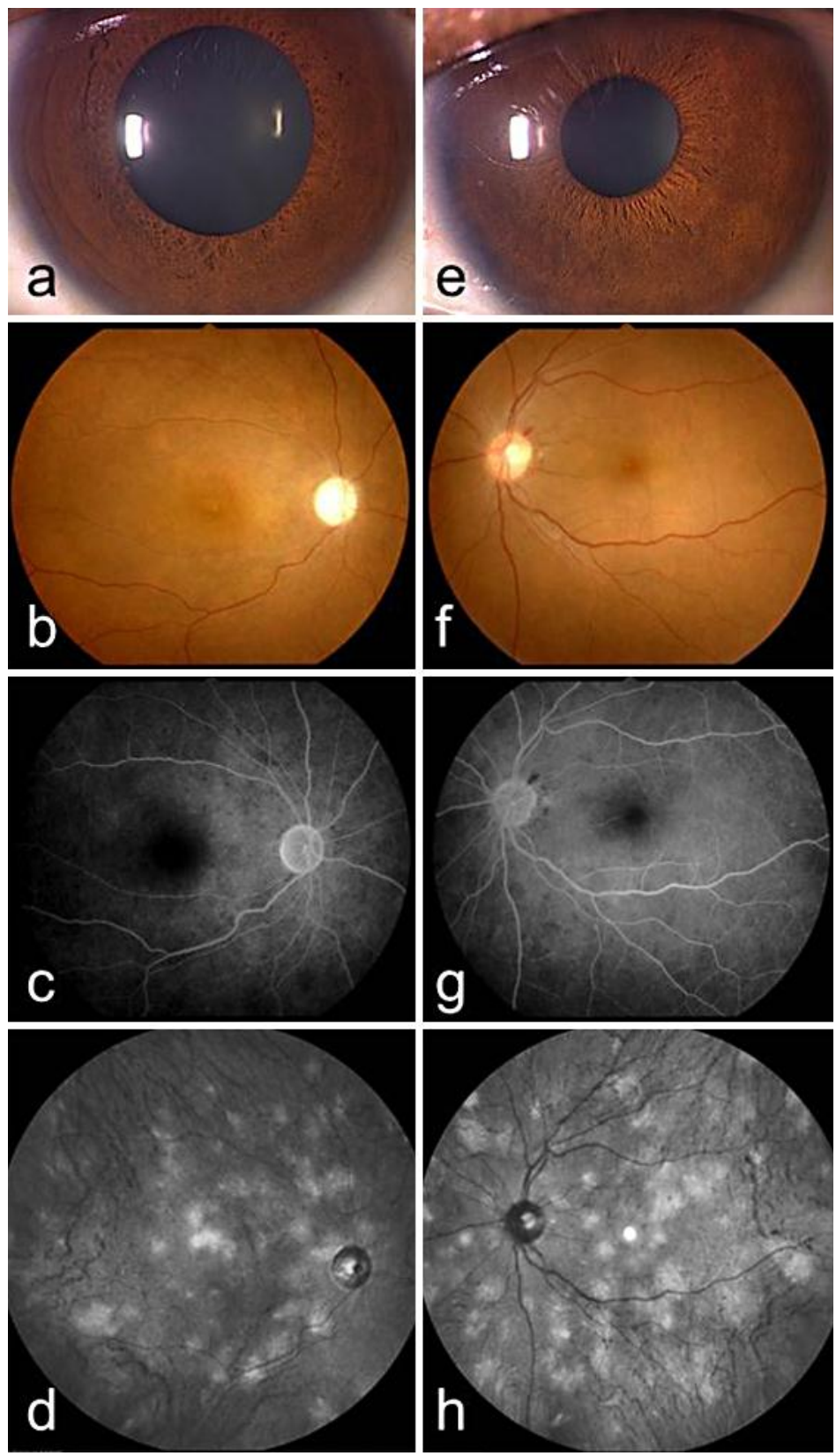

Fig. 1. Findings for a 42-year-old woman with SLE in her right (a-d) and left (e-h) eye. No abnormalities are observed in her iris (a, d). Fundus photographs show no specific retinochoroidal abnormalities in either eye, with the exception of optic disc atrophy in her right eye (b) and a peripapillary small hemorrhage in her left eye (f). Fluorescein angiography reveals no dye leakage or pooling (c, g). NIR images reveal multiple bright patchy lesions in the posterior pole and in the mid-periphery of the fundus of both eyes (d, h). The hyperreflective point at the center of the image is an optical artifact. 
Case Reports in

Ophthalmology
Case Rep Ophthalmol 2013;4:81-86

DOI: $10.1159 / 000354288$

Makino et al.: Rare and Unusual Choroidal Abnormalities in a Patient with Systemic
Lupus Erythematosus

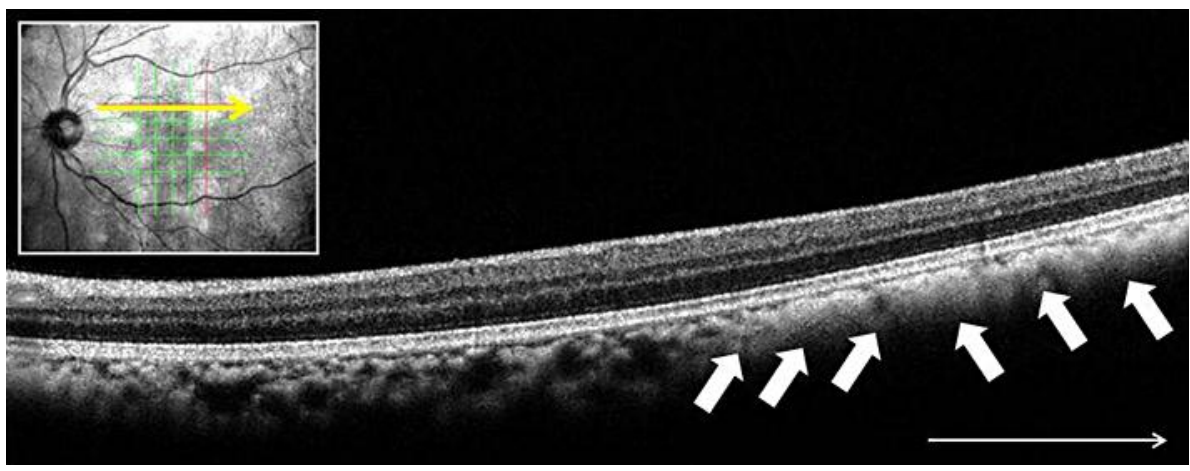

Fig. 2. Horizontal OCT findings in a 42-year-old woman with SLE in her left eye. Note the irregular hyperreflectance foci in the choroid (arrows). 